\title{
Interaction between head fire and backfire in grasslands
}

\author{
Dominique Morvan ${ }^{\mathrm{a}, *}$, Sofiane Meradji ${ }^{\mathrm{b}}$, William Mell $^{\mathrm{c}}$ \\ a Aix-Marseille Université, Laboratoire M2P2 UMR CNRS 6181, UNIMECA Technopôle de Château Gombert, 60 rue Joliot Curie, 13453 \\ Marscille, Marseille cedex 13, France \\ b Université du Sud Toulon-Var, Laboratoire IMATH, Bâtiment U BP 20132-83957 La Garde Cedex, France \\ ${ }^{c}$ US Forest Service Pacific Northwest Research Station, Pacific Wildland Fire Science Laboratory, 400N, 34th Street, Suite 201 Seatle, WA 98103, USA
}

\begin{abstract}
This paper deals with 3D numerical simulations of two fires fronts (head and backfire) propagating simultaneously through a grassland fuel. The simulations were carried out using a "fully" physical and three-dimensional fire model (namely WFDS). One of the objectives of this work, was to evaluate the potential for fully physical fire model to simulate the interactions between two fire fronts (a head fire and a backfire), in conditions similar to those encountered during suppression fire operations. A set of numerical simulations was first carried out for standalone head fires propagating through grasslands on a flat terrain and for various wind conditions ranging between 1 and $10 \mathrm{~m} / \mathrm{s}$. These results were compared with experimental data and numerical results from the literature. The same calculations were then repeated, with a backfire ignited at the downwind side of the plot. The numerical results highlighted that, for these particular conditions, head fire and backfire can interact, mainly, via two mechanisms:

- at relatively large distances (greater than $10 \mathrm{~m}$ ) the head fire acts on backfire as a screen and reduces the direct action of the wind flow on the backfire,

- at relative small distances (nearly equal to $10 \mathrm{~m}$ ) the gas flow (entrainment) generated in the vicinity of the head fire promotes the aspiration of the backfire towards the main fire front.
\end{abstract}

\section{Introduction}

The reduction of fuel located between the fire front and a control line constitutes one of the most efficient methods of stopping or reducing the propagation of a fully developed wildland fire. This operation can be accomplished by using mechanical means (bulldozer) or by using a suppression fire (also called counter fire or backfire) [1]. During the last decades this traditional technique was reintroduced as an alternative tool when classical terrestrial or aerial means were non operational (e.g. during the night) or not sufficiently efficient.

As indicated by Goldammer and De Ronde [2], one can formally distinguish two techniques for reducing fuel: burn out operations and backfiring operations. Burn out operations use techniques very similar to prescribed burning with the goal to burn the vegetation located between the main fire and the control line. The use of a backfire is more aggressive, and consists in igniting a fire line as close as possible to the main fire front. In this case, both fire fronts propagate in opposite directions before

\footnotetext{
* Corresponding author. Tel.: +33 491113851.

E-mail address: dominique.morvan@univ-amu.fr (D. Morvan).
}

merging. Firefighters or foresters in charge of burn out or backfiring operations have to determine optimal environmental conditions for success. This includes the influence of terrain slope, wind conditions and, more generally air flow conditions in the vicinity of the two fire fronts, to guarantee the success of this kind of operation. In a successful backfire operation, all the available solid-fuel located ahead of the main fire front is consumed and the progression of the wildfire is blocked and the fire is rapidly extinguished [1-3]. The main basis for the use of backfiring to fight wildfires remains for a large part empirical [3,4]. The ideal condition for backfire success is expected to be met when the fire induced winds created by the main fire front entrain the back fire.

Very few studies have been published on this subject, for example it is not well known at what separation distance (as a function of the fireline intensity) significant interaction between the back and head fires occurs (in-draft distance). By head fires we mean fires that are spread in the same direction as the ambient wind; backfires spread a direction opposite to that of the ambient wind. Few fundamental studies are published on this subject, at the laboratory scale we can cite experimental fires carried out in fuel beds [5]. At the field scale similar to operational conditions, the propagation and interaction of head fires and backfires, ignited simultaneously in small plots of shrubland, 
were studied recently in the the EU project FireParadox [6,7]. All experimental field observations showed that, once the distance separating the two fire fronts was smaller than a threshold value ( $5 \mathrm{~m}$ in pine needles litter and $20 \mathrm{~m}$ in shrubs), the two fires accelerated, indicating a mutual interaction between the two fires. During the same EU project (FireParadox), Dupuy et al. [8,9], performed 3D numerical simulations of head fire and backfire ignited on a flat terrain in grassland, using a 3D code (FIRETEC) developed at the Los Alamos National Laboratory [10]. In these numerical results an in-draft flow ahead of a surface fire existed in a limited numbers of situations when the distance between the two fire fronts was smaller than $10 \mathrm{~m}$. The authors identified also another mechanism contributing to the interaction between two fire fronts, the shelter effect caused by the convective plume above the head fire and protecting the backfire from the direct action of the wind flow. Unfortunately, these preliminary numerical simulations were carried out using a mesh size at least 4 times larger than the extinction length scale, with the consequence, that in many cases the backfire was not able to propagate.

A numerical study in 2D (using FDS) was proposed by Roxburgh and Rein [11], to calculate the flow field observed around a wildfire. In this study the fire front was represented as a fixed burner on a bare flat terrain, the fire intensities ranged between 1 and $10 \mathrm{MW} / \mathrm{m}$. The numerical results highlighted that the flow field in the vicinity of the fire front can be separated into three regions: zone 1 is closest to the fire front and directly affected by the flame, zone 2 is located at the maximum value of the module of the in-draft flow, zone 3 is farthest from the fire front and dominated by the external flow. The simulations showed clearly that the size of zone 2 , which is the most favourable zone for the ignition of a backfire, increased as the fire intensity increased, and that the in-draft distance varied from $15 \mathrm{~m}$ to $70 \mathrm{~m}$.

More recently Morvan et al. [19,20], proposed a numerical study, carried out using a detailed forest fire physical model $[12,13]$, to simulate the interaction between a head fire and a backfire propagating through grass or shrubs. Even if this study was limited to a 2D configuration, which constitutes a simplification from the reality, many physical phenomena observed in real situations were reproduced in these simulations. For example, the numerical results highlighted that the two fire fronts can only interact at a short distance (ranges between $10 \mathrm{~m}$ and $20 \mathrm{~m}$ ). As indicated by Dupuy et al. [8], this interaction between the two fire fronts resulted mainly from a shelter effect induced by the convective plume developing above the head fire and protecting the backfire from the direct action of the ambient wind flow. This study also showed that in some circumstances, the flame height and the heat release rate can exhibit a sudden increase as the fire fronts merged.

Using a Coupled Atmosphere-Wildland Fire-Environment model (CAWFE), Coen [14] showed that the up-draft flow resulting from the buoyancy force inside the convective plume above an intense fire, can reach vertical velocities two times larger than those measured in a supercellular storm [15]. This very strong vertical flow induces by continuity (mass conservation) - an intense horizontal in-draft flow at the base of the fire front; this mechanism is often referenced in the literature as fire-induced wind [16]. The simulations [14] also highlighted that the interaction phase preceding the merging between the two fire fronts contributed to an acceleration of the fire growth.

One condition of a successful backfire operation is the identification of conditions that allow propagation of a backfire into the wind. This problem presents some similarities with reverse combustion in a packed bed, which has been studied (both experimentally and numerically) in more fundamental configurations $[12,17,18]$. Both experimental data and numerical results, showed that reverse combustion in a packed bed was mainly controlled by radiation heat transfer coming from the solid-fuel layer. Two regimes of propagation were clearly identified, namely oxygen-limited and fuel-limited. For the oxygen-limited regime, the reverse air flow promotes the propagation of the combustion front, whereas for the fuel-limited regime the reverse air flow reduces and, above a threshold value, can stop the propagation of the combustion front.

Previous numerical simulations $[19,20]$ showed that the rate of spread of backfires was weakly affected by an increase of the incoming wind flow. This information seems to confirm the idea that for moderate wind conditions, the regime of propagation of backfires can be identified near the limit between oxygen-limited and fuel-limited regimes which corresponds to a stoichiometric burning $[12,17,18]$. If the incoming wind flow is small or if backfire is protected by another fire front (as is the case during a suppression fire operation), the air flow in the vicinity of the backfire, results directly from the action of the fire itself upon its environment. To maintain quasi-steady state conditions of propagation, there is a self-regulation of the system to ensure an optimal air supply ahead of the fire front, directly correlated with the production of combustible gas from the pyrolysis process (stoichiometric burning).

Experimental fires, carried out in Savanna vegetation in South Africa, showed that for every physical characteristics of fire behaviour (rate of spread, fire intensity, and flame height), head fires were much more intense than backfires. It was found that the fire intensity and rate of spread (ROS) of the head fire were greater than the backfire by a factor of 7, and flame height was multiplied by a factor of $3[2,21]$. Results also showed that head fires were much more affected by external conditions (such as wind) than backfires and that because the fire residence time was larger for backfires than for head fires, the temperature measured at the ground level for backfires was larger than those measured for head fires.

The problem of the interaction of multiple fires was also studied experimentally on an arrangement of a set of static burners [22]. It was observed that the combustion rate increased as the average distance separating two burners decreased. This phenomenon seems to be a consequence of the transition between an individual and a collective behaviour (massive fire). Then this indicator of combustion efficiency reached an optimal value, before decreasing. This saturation phenomena could result from the reduction of air supply in the region located between two adjacent burners.

In this paper, the problem of the interaction between two fire fronts is studied numerically. This work constitutes a continuation and an extension (in 3D) of previous 2D numerical simulations $[19,20]$. Some preliminary results have been already presented by Morvan et al. [24]. One of the objectives of the present study was to identify the physical phenomena occurring before and during the merging between the two fire fronts (head fire and backfire) in free propagation through a homogeneous fuel layer, such as grassland.

\section{Physical and mathematical model}

The numerical simulations were carried out using WFDS (Wildland Urban Interface Fire Dynamics Simulator) which is an extension of FDS5 (Fire Dynamics Simulator Version 5.2) initially developed to simulate fire growth and smoke transport for outdoor fires and structural fires $[25,26]$. The approach used in WFDS to simulate the behaviour of forest fire can be classified as a physical approach, following the classification reported in a recent review paper [27]. The model is based on a multiphase CFD approach, consisting in solving a reaction, turbulent fluid flow problem in the atmospheric layer at the vicinity of the fire front, 
coupled with a solid-fuel degradation sub-model inside the vegetation layer. Taking into account that the gas velocity was largely sub-sonic, and that the behaviour of the fire was not affected by acoustic waves, the treatment of the equation of state was simplified using a low Mach number approximation. Compared to a fully compressible model, this approximation allows for considerably larger time steps [20] and consequently, reduced the CPU times for a given simulation.

Without describing all the mathematical equations composing the model in detail [26], the present wildfire physical model was based on the following concepts. To take into account the existence of two levels of sub-grid scale phenomena (the turbulence motions of the atmosphere and the solid-fuel elements composing the vegetation), the Navier-Stokes equations were filtered two times. The first step (explicit) consists in averaging the effects induced by the presence of small scale solid-fuel particles (foliage and twigs) which cannot be directly represented in the model and were replaced by equivalent continuum media, using a procedure similar to an homogenisation process used to simulate fluid flow in complex porous media [28]. The second step (implicit) consists in applying Navier-Stokes equations, the same procedure used for Large Eddy Simulations (LES), in assimilating the effects induced by the small structures of turbulence upon the large structures as an additional diffusion process (eddy diffusion concept). After these two-steps of averaging, the resulting equations governing the behaviour of the system include some additional terms, representing the interaction between the gaseous phase with the vegetation (first step) and the correlation terms representing the sub-grid scale transport contribution (second step). One of consequences of the first averaging step, is the introduction of drag force in the momentum equations, this term is proportional to the square of the average velocity and to the leaf area density (LAD) which is denoted by $A$. The LAD is proportional to the product of the vegetation volume fraction and the surface-area to volume ratio characterising the solid-fuel elements comprising the vegetation layer $[20,26]$ :

$\left\langle f_{D, i}\right\rangle=-\bar{\rho} C_{D} A|\tilde{u}| \tilde{u}_{i}$

The value of the average drag coefficient $C_{D}$, used in the present numerical simulations, was evaluated as a function of the local Reynolds number based on the solid-fuel particle size [26].

The Sub Grid Scale (SGS) model used in the LES approach is similar to a constant coefficient in the Smagorinsky model, with an eddy viscosity of $v_{T}$ is calculated as follows:

$v_{T}=\left(C_{S} \Delta^{2}\right)|\bar{S}| \Delta=\left(\Delta_{x} \times \Delta_{y} \times \Delta_{z}\right)^{1 / 3}$

where $\Delta_{x}, \Delta_{y}, \Delta_{z}$ represent the grid size along the three directions of space, $S$ is the magnitude of the strain rate and $C_{S}$ is the Smagorinsky constant equal to 0.2 .

The combustion in the gaseous phase was solved, assuming a single step kinetics chemical reaction [26]:

$$
\mathrm{C}_{3.4} \mathrm{H}_{6.2} \mathrm{O}_{2.5}+3.7\left(\mathrm{O}_{2}+3.76 \mathrm{~N}_{2}\right) \rightarrow 3.4 \mathrm{CO}_{2}+3.1 \mathrm{H}_{2} \mathrm{O}+13.91 \mathrm{~N}_{2}
$$

Assuming that the mixing of gaseous fuel coming from thermal decomposition of the vegetation and the ambient air constitutes the limiting factor for the combustion reaction, the reaction rate in the gaseous phase was evaluated using the Eddy Dissipation Concept (EDC) $[25,26]$ as follows:

$\bar{m}_{F}^{\prime \prime}=-\frac{\bar{\rho} \min \left(\tilde{Y}_{F}, r_{O_{2}} \tilde{Y}_{O_{2}}\right)}{\tau}, \tau=C_{E D C} \frac{\Delta^{2} S_{C T}}{v_{T}}, \quad C_{E D C}=0.1$

Concerning the treatment of the vegetation, the surface fuel layer can be represented in two manners in WFDS:

- Using a boundary fuel model, in which the energy balance for the vegetative fuel layer is solved on its own computational grid which interfaces with the computational grid for the gas phase. In this case, the interactions between the two phases (solid-fuel layer and surrounding atmosphere) are limited to heat and mass flow at the interface between the two media [29].

- Using a fuel element model, in which the fuel elements composing the vegetation stratum, are fully immersed inside the gaseous phase (as a sparse porous media). In this case the interaction between the two phases have been represented using volume source/sink terms in mass, energy and momentum balance equations [26]. This formulation is similar to the approach proposed by Morvan et al. [13,30,31]. This formulation is used in the present paper.

Considering the complexity of physical phenomena occurring in wildfire modelling, including numerous non linear processes, such as radiation heat transfer, chemical reaction in the gaseous phase, turbulent transfers, it is difficult to consider that such model can be fully validated. It is for this reason that concerning WFDS (this remark is also true for all other similar simulation tools), we can only say that WFDS has been partially validated for surface fires propagating in grassland [29] and for burnings of Douglas fir trees [26]. All the developments done in the frame of WFDS project (especially the fuel elements concept) have been now fully integrated in the current version of FDS.

\section{Results and discussion}

As a preliminary step, we performed a set of numerical simulations, by igniting one line fire in a $20 \mathrm{~m} \times 50 \mathrm{~m}$ (width $\times$ length; ambient wind is along the length dimension) grassland plot. The physical properties characterising this homogeneous fuel layer were identical to those chosen for a previous numerical study [32], and listed in Table 1. They can be considered as similar to conditions encountered during the reference large scale experimental campaigns carried out in Australia [33], and most often used for the validation of physical fire models [31,34]. To minimise the effects of some uncertainties, concerning the open boundary conditions, this fuel plot was immersed inside a larger domain without any vegetation (width $=120 \mathrm{~m}$ and length $=130 \mathrm{~m}$ ). The upper limit, where open boundary conditions are imposed, was fixed $40 \mathrm{~m}$ above the ground level. We have verified that this arbitrary choice did not affect the numerical results, and especially the behaviour of the fire front. In order to simulate the propagation of surface fires in various wind conditions (for moderate and strong wind conditions, for head fire and backfire), the computational domain was discretised using a relatively fine grid mesh size $\Delta x=\Delta y=0.25 \mathrm{~m}$ (two times smaller than the extinction length scale, $\delta_{R}=0.5 \mathrm{~m}$ ). We chose a variable grid mesh along the vertical direction, $\Delta z$ ranged between $0.05 \mathrm{~m}$ near the ground to $2 \mathrm{~m}$ at the top of the computational domain. At the inlet of the domain (on the left end side), a power law velocity profile was imposed (with an exponent equal to $1 / 7$, corresponding to the situation encountered

Table 1

Physical properties characterising the fuel layer used for the calculation performed in grassland.

\begin{tabular}{lc}
\hline Fuel density $\left(\mathrm{kg} / \mathrm{m}^{3}\right)$ & 500 \\
Fuel packing ratio $\times 10^{3}$ & 2 \\
Fuel moisture content $(\%)$ & 5 \\
Fuel depth $(\mathrm{m})$ & 0.7 \\
Surface area to volume ratio $\left(\mathrm{m}^{-1}\right)$ & 4000 \\
Leaf area index $\left(\mathrm{LAI}=\mathrm{LAD} \times \mathrm{H}_{\text {Fuel }}\right)$ & 2.8
\end{tabular}


$U_{X}(Z)=U_{H}\left(\frac{Z}{H}\right)^{1 / 7}$

The reference height $H$ was fixed to be equal to $10 \mathrm{~m}$, consequently the reference velocity chosen as the main parameter to analyse the numerical results was equal to $10 \mathrm{~m}$ open wind velocity $U_{10}$. Before igniting the line fire, the flow field was initialised during a duration equal to $120 \mathrm{~s}\left(U_{10}=1 \mathrm{~m} / \mathrm{s}\right), 40 \mathrm{~s}\left(U_{10}=3 \mathrm{~m} / \mathrm{s}\right)$ and $30 \mathrm{~s}$ $\left(U_{10}=5,8\right.$ and $\left.10 \mathrm{~m} / \mathrm{s}\right)$.

The heat release rate (HRR $>135 \mathrm{~kW} / \mathrm{m}^{3}$, in orange), the soot volume fraction (in black) and the surface temperature of the solid fuel layer $\left({ }^{\circ} \mathrm{C}\right)$, calculated for four values of wind speed $(1,3$, 8 and $10 \mathrm{~m} / \mathrm{s}$ ), are represented in Figs. 1 and 2. For the two smallest values of the wind speed (Fig. $1, U_{10}=1$ and $3 \mathrm{~m} / \mathrm{s}$ ), after a transient period (10-15 s after the ignition) the behaviour of the fire reached a quasi steady state, characterised by nearly constant values for the rate of spread (ROS) and the heat release rate HRR.

It is well known that the behaviour of surface fires is greatly affected by the ratio between two forces: the inertia due to the wind flow and the buoyancy resulting from the gradient of density between the interior of the plume with the ambient air [35]. The ratio between these two forces defines a dimensionless



Fig. 1. Surface fire propagating through a grassland for two values of the wind speed $U_{10}=1 \mathrm{~m} / \mathrm{s}$ (on top) and $3 \mathrm{~m} / \mathrm{s}$ (on bottom). Heat release rate (in orange), smoke volume fraction (in black) and surface temperature $\left({ }^{\circ} \mathrm{C}\right.$ ) of solid fuel (in colour). (For interpretation of the references to colour in this figure legend, the reader is referred to the web version of this article.)

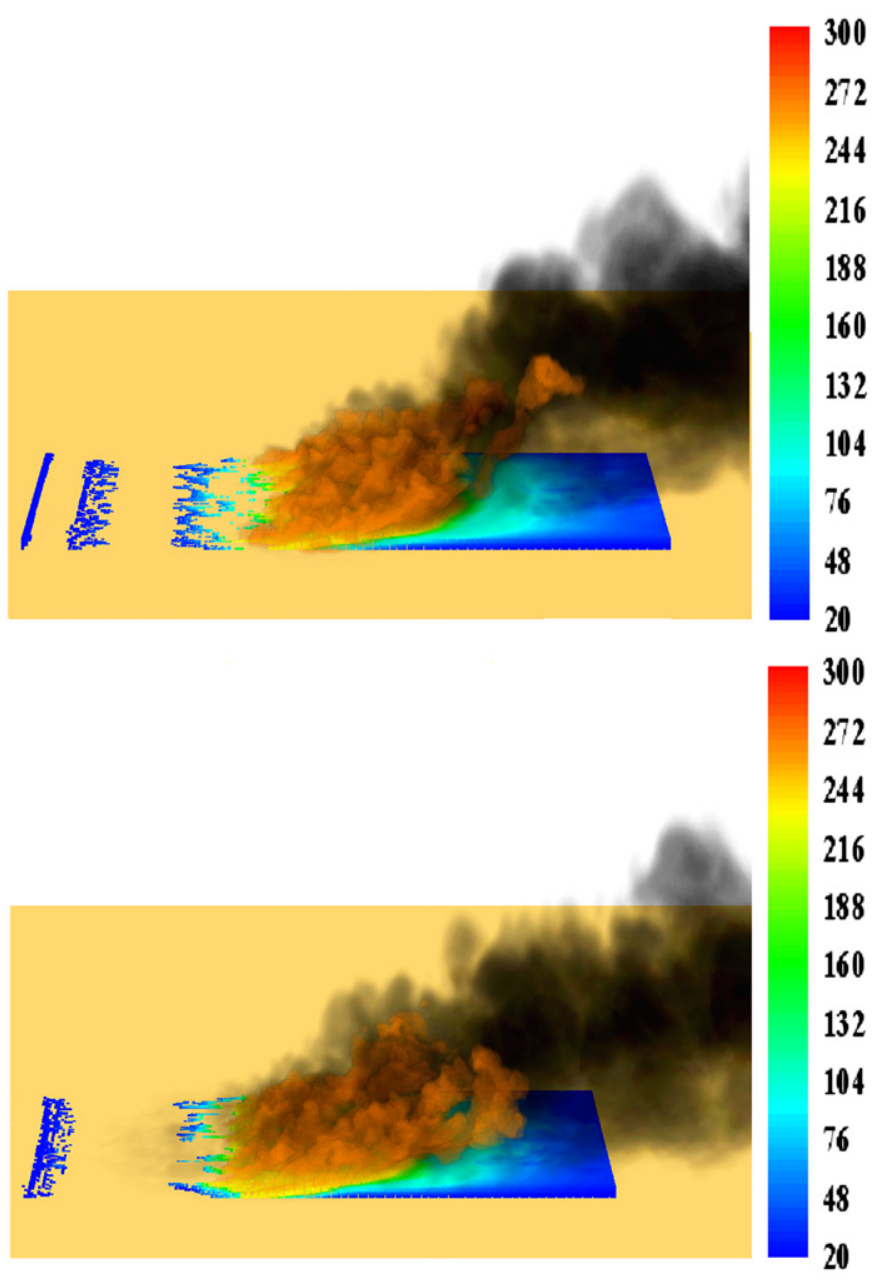

Fig. 2. Surface fire propagating through a grassland for two values of the wind speed $U_{10}=8 \mathrm{~m} / \mathrm{s}$ (on top) and $10 \mathrm{~m} / \mathrm{s}$ (on bottom): heat release rate (in orange), smoke volume fraction (in black) and surface temperature $\left({ }^{\circ} \mathrm{C}\right.$ ) of solid fuel (in colour). (For interpretation of the references to colour in this figure legend, the reader is referred to the web version of this article.)

number $F_{r}$ (Froude number) [36]:

$F_{r}=\frac{C_{10}^{2}}{g H_{\text {Fuel }}}$

Here $H_{\text {Fuel }}$ is the fuel layer depth. For $U_{10}$ equal to $1 \mathrm{~m} / \mathrm{s}$ and $3 \mathrm{~m} / \mathrm{s}$, the corresponding values for the Froude number were 0.15 and 1.31 , respectively, indicating that under these conditions the behaviour of fire presented similarities with a "plume dominated fire" [35] (quasi-vertical plume and radiation heat transfer between fire and vegetation are the significant contributors to fire spread). Results for the two largest values of wind speed $\left(U_{10}=8\right.$ and $\left.10 \mathrm{~m} / \mathrm{s}\right)$ are plotted in Fig. 2 . For these wind speeds the Froude number is $9.32\left(U_{10}=8 \mathrm{~m} / \mathrm{s}\right)$ and $14.56\left(U_{10}=10 \mathrm{~m} / \mathrm{s}\right)$. Although the length of the plot $(50 \mathrm{~m})$ was not large enough for the fire to reach a quasi-steady state propagation, many elements, such as the longitudinal depth of the fire front and the larger values for the Froude number indicate that the regime of propagation of these fires can be classified as a "wind driven fires" [37].

The evolution of the ROS (evaluated from the trajectory of the pyrolysis front, characterised using the isotherm in the fuel layer, $T=500 \mathrm{~K})$ versus the $10 \mathrm{~m}$ open wind velocity $\left(U_{10}\right)$ are shown in Fig. 3. The present results were compared with observations obtained from experimental fires in grassland in Australia [33], with other numerical results obtained in 2D (FIRESTAR, [31]) and 3D (FIRETEC, [32]) and with predictions obtained using two 


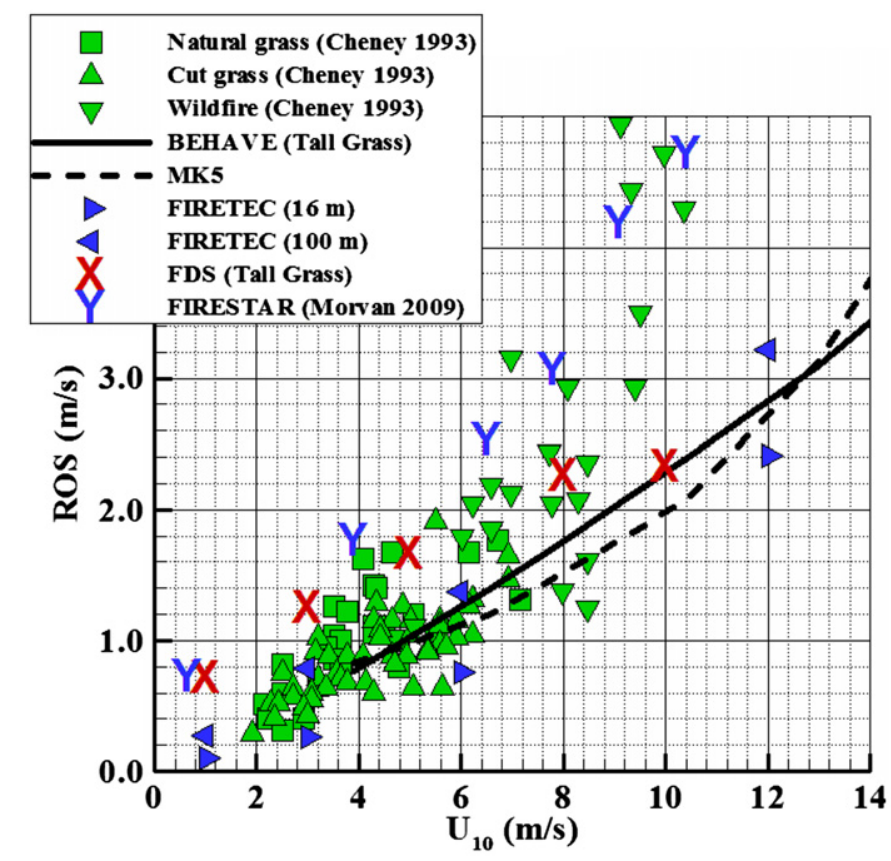

Fig. 3. Rate of spread (ROS) versus $10 \mathrm{~m}$ open wind speed velocity $\left(U_{10}\right)$ in grassland (FDS $=$ WFDS), compared to experimental observation carried out in Australia (Cheney et al. [33]), to numerical results obtained using FIRESTAR (Morvan et al. [19]) and FIRETEC (Linn et al. [32]) and to predictions obtained using two operational models (BEHAVE+MK5) (Andrews [39], Mc Arthur [38]).

operational models MK5 [38] and BehavePlus [39]. Despite the relative dispersion of experimental data, we can conclude that for moderate wind speed conditions (until $8 \mathrm{~m} / \mathrm{s}$ ), the results obtained using WFDS and FIRESTAR are relatively in good agreement, and fitted well the general trend observed on the field. We noticed that FIRETEC predicted smaller values for the ROS, similar to those obtained using BehavePlus and MK5. For moderately strong wind conditions ( $>8 \mathrm{~m} / \mathrm{s}$ ), except for the results obtained using FIRESTAR, all models (WFDS, FIRETEC, BehavePlus, and MK5) under-predicted the ROS (in comparison with field data). For empirical (MK5) and semi-empirical (BehavePlus) models, it is easy to understand that statistical relations, obtained for moderate wind conditions (MK5) or extracted from small scale laboratory fires (BehavePlus), cannot be successfully extrapolated for more severe wind conditions and for large scale fires. For WFDS and FIRETEC one source of difference between simulated and observed spread rates could be the coupling between turbulence and radiation heat transfer (TRI) which is not explicitly taken into account in these two models and which is far from negligible in this problem $[20,40]$. For WFDS we must also underline, that the present results were obtained for a $20 \mathrm{~m}$ long ignition line fire, we know from experimental observation [41], that the ROS decreased exponentially with the ignition fire width (with an asymptotical value reached for a fire line larger than $200 \mathrm{~m}$ ). The WFDS value of the rate of spread (ROS) obtained for $U_{10}=10 \mathrm{~m} / \mathrm{s}$ (Fig. 3) did not therefore, correspond to the ROS normally attached to a nearly steady state fire propagation (which must be larger) since the longitudinal dimension of the plot $(50 \mathrm{~m})$ was certainly too short to achieve this regime.

The same configuration, in grassland, was used again to study the interaction between two fire fronts, simultaneously ignited at the two sides of the plot and for four values of the wind speed $U_{10}=1,3,5$ and $8 \mathrm{~m} / \mathrm{s}$. The corresponding values of the Froude number were equal to $0.15,1.31,3.64$ and 9.32 . Based on these Froude numbers, the four simulations were representative of head fires in plume dominated, intermediate, and wind driven fires

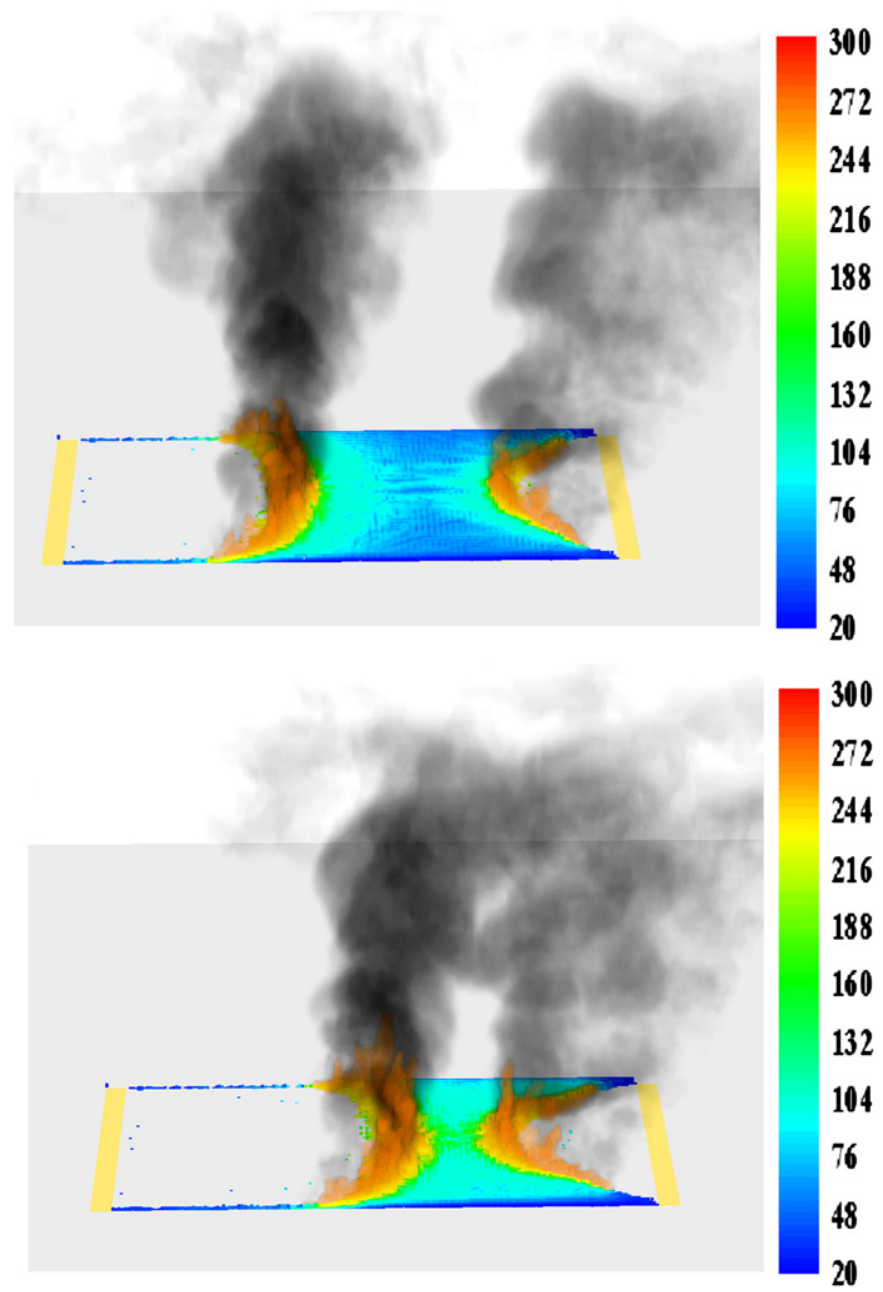

Fig. 4. Head fire and backfire propagating through grassland $\left(U_{10}=1 \mathrm{~m} / \mathrm{s}\right)$ at times $t=153 \mathrm{~s}$ (top) and $160 \mathrm{~s}$ ( bottom). Heat release rate (in orange), smoke volume fraction (in black) and surface temperature $\left({ }^{\circ} \mathrm{C}\right.$ ) of solid fuel (in colour). (For interpretation of the references to colour in this figure legend, the reader is referred to the web version of this article.)

conditions (for two last cases). The results shown in Figs. 4 and 5, are four snapshots characterising the situation in terms of HRR surface $\left(>135 \mathrm{~kW} / \mathrm{m}^{3}\right)$, soot volume fraction and surface fuel temperature at four different times during the propagation of the back and head fire fronts. The ambient wind speed of $U_{10}=1 \mathrm{~m} / \mathrm{s}$ :

- when the distance separating the two fire fronts is too large to allow an interaction between them (Fig. 4 on top),

- when the distance separating the two fire fronts is less than $10 \mathrm{~m}$, promoting a sudden increase of intensity for the two fires (Fig. 4 on bottom),

- during the merge between the two fire fronts (Fig. 5 on top), and

- at the end of numerical experiment, just before the complete extinction (Fig. 5 on bottom).

In comparing the two images represented in Fig. 4, it is clear that the interaction between the two fires is bidirectional, i.e. the head fire acted on backfire and vice-versa. As the distance separating the two fire fronts becomes less than a threshold value (ranges between 10 and $20 \mathrm{~m}$ ), the intensity of the two fire fronts, increases rapidly, i.e. both the backfire and the head fire had an action upon the other one. To highlight more easily the consequences resulting from the interaction between the two fire 


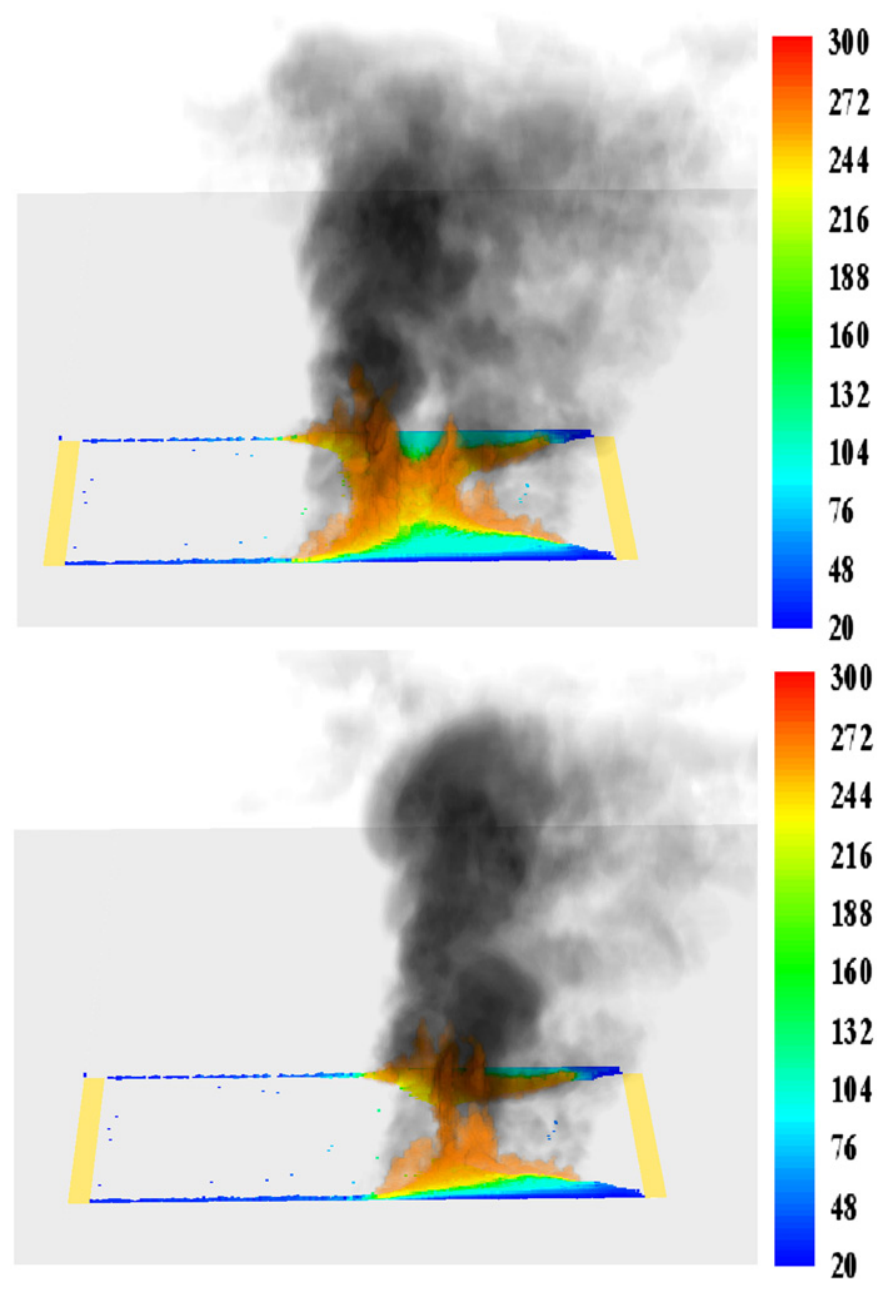

Fig. 5. Head fire and backfire propagating through grassland $\left(U_{10}=1 \mathrm{~m} / \mathrm{s}\right)$ at times $t=163 \mathrm{~s}$ (top) and $168 \mathrm{~s}$ ( bottom). Heat release rate (in orange), smoke volume fraction (in black) and surface temperature $\left({ }^{\circ} \mathrm{C}\right.$ ) of solid fuel (in colour). (For interpretation of the references to colour in this figure legend, the reader is referred to the web version of this article.)

fronts, the time evolution of the total heat release rate (HRR) is plotted in Fig. 6. We have reproduced two curves obtained without and with ignition of a backfire. During the initial phase (until $150 \mathrm{~s}$ after ignition), the difference between the two curves is due to the contribution of the backfire. Then, we can noticed a significant increase $(+50 \%$ within $30 \mathrm{~s})$ of the HRR, during the approach and merging phase of the two fires.

The evolution of the behaviour of both the head and back fires and the coupling with the aerology around the burning zones can also be observed in Fig. 7, which shows the gas temperature $\left({ }^{\circ} \mathrm{C}\right)$ and the streamlines in a median vertical plane parallel to the direction of propagation. Concerning the fire dynamics, the sudden increase of fire intensity, observed when the two fire fronts were relatively close, is particularly well highlighted (see Fig. 7 on bottom). In comparing Fig. 7 on top and bottom, this effect is more noticable upon the backfire behaviour. In Fig. 8 streamlines starting upstream of the head fire at $1 \mathrm{~m}$ above the ground level are plotted along with the fire fronts (represented by one isovalue of the HRR) in Fig. 8. This Figure highlights that, for weak wind conditions, the thermal plume constitutes a quasi impassable barrier for the incoming wind flow, which cannot cross the fire front (head fire). In this case, the major part of the wind flow arriving at the fire foot, is entrained vertically by the thermal plume.

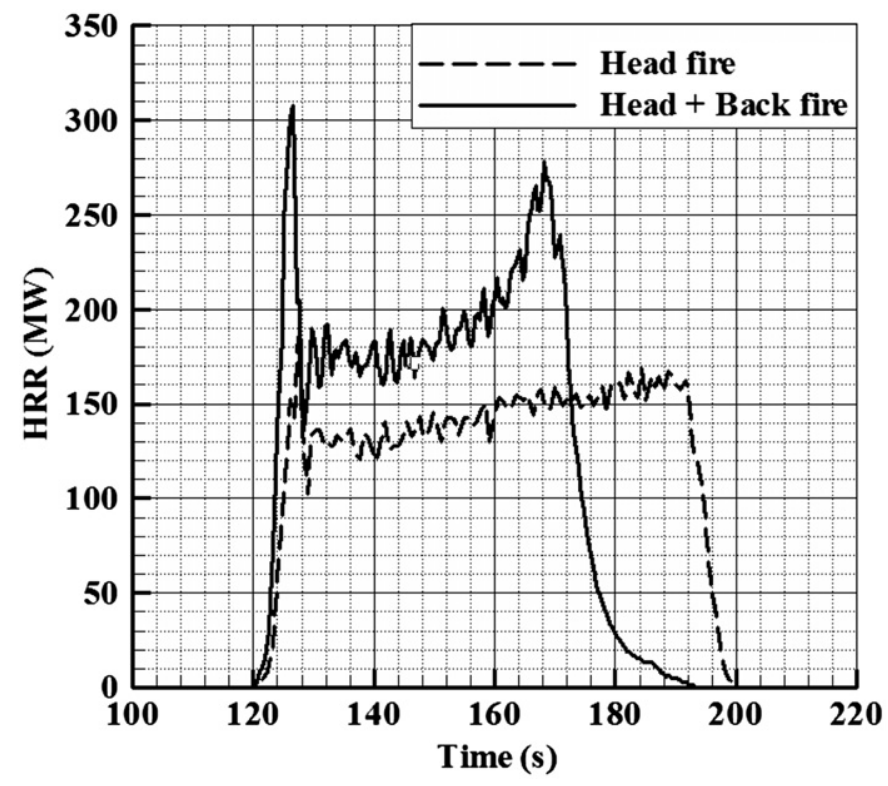

Fig. 6. Heat release rate (HRR) for a standalone head fire and for a head + backfire $\left(U_{10}=1 \mathrm{~m} / \mathrm{s}\right)$


Fig. 7. Temperature field $\left({ }^{\circ} \mathrm{C}\right)$ and streamlines in a streamwise plane $\left(U_{10}=1 \mathrm{~m} / \mathrm{s}\right)$ at times $t=153 \mathrm{~s}$ and $163 \mathrm{~s}$ (median plan $Y=0$ ).

The same calculation is plotted for two other values of the wind speed $U_{10}=3 \mathrm{~m} / \mathrm{s}$ (Figs. 9-11), and $U_{10}=5 \mathrm{~m} / \mathrm{s}$ (Figs. 12-14). For $U_{10}=3 \mathrm{~m} / \mathrm{s}$, even if the plume was more affected by the lateral wind flow, the trajectory of flames stayed more or less vertical (as shown in Figs. 9 and 11). The new information highlighted with this configuration, was that during a long time we did not observe a significant difference between the two curves representing the time evolution of the total HRR for the case with only a head fire and for the case with both head and back fires (see Fig. 10), indicating that during the same period, backfire was not able to propagate through the fuel layer. At the end of the experiment, as in the previous case, we noticed an increase $(+45 \%$, over $10 \mathrm{~s})$ of the HRR (see Fig. 10), indicating that the backfire was suddenly able to propagate. The action of the head fire upon the backfire resulted here from the same physical mechanism was discussed in the previous case, i.e. the in-draft flow induced at short distance by the head fire plume rising above the major fire front (see Fig. 11), contributed in drawing the backfire flame towards the unburned vegetation separating the two fire fronts. We know 


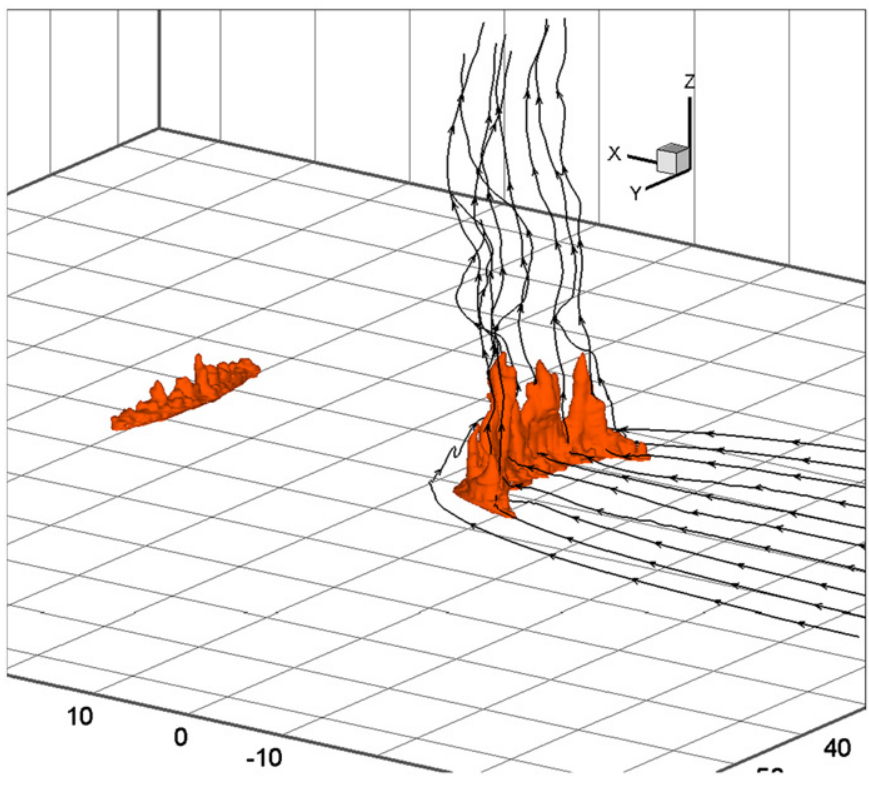

Fig. 8. Streamlines emitted at a height $z=1 \mathrm{~m}$, upstream the main fire front for $10 \mathrm{~m}$ open wind speed $U_{10}=1 \mathrm{~m} / \mathrm{s}$.


Fig. 9. Head fire and backfire propagating through grassland $\left(U_{10}=3 \mathrm{~m} / \mathrm{s}\right)$ at times $t=68 \mathrm{~s}$ (top) and $71 \mathrm{~s}$ (bottom). Heat release rate (in orange), smoke volume fraction (in black) and surface temperature $\left({ }^{\circ} \mathrm{C}\right.$ ) of solid fuel (in colour). (For interpretation of the references to colour in this figure legend, the reader is referred to the web version of this article.)



Fig. 10. Heat release rate (HRR) for a standalone head fire and for a head + backfire $\left(U_{10}=3 \mathrm{~m} / \mathrm{s}\right)$.

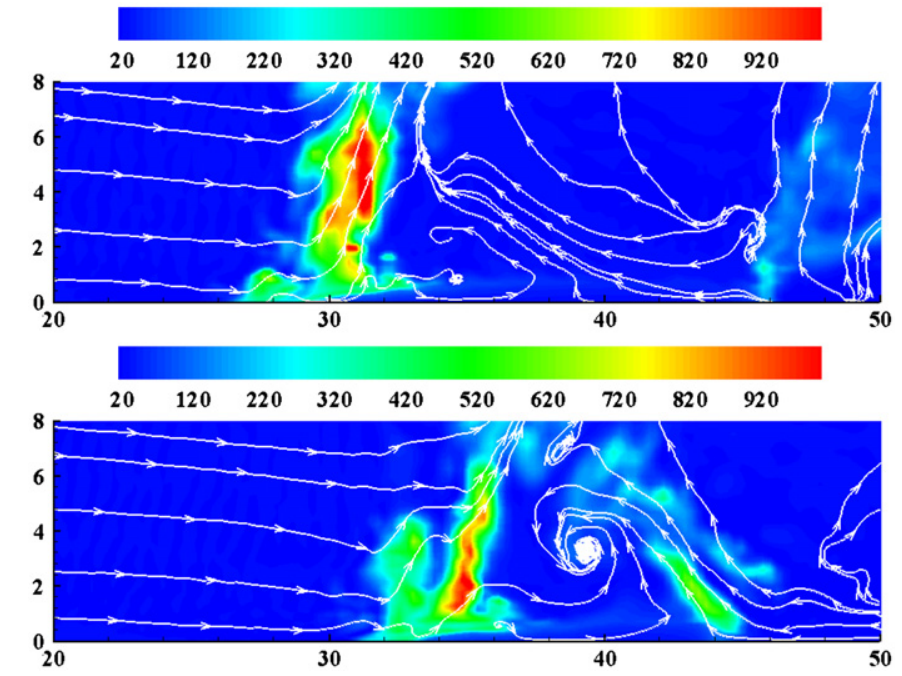

Fig. 11. Temperature field $\left({ }^{\circ} \mathrm{C}\right)$ and streamlines in a streamwise plane $\left(U_{10}=3 \mathrm{~m} / \mathrm{s}\right)$ at times $t=68 \mathrm{~s}$ and $71 \mathrm{~s}($ plan $Y=-5 \mathrm{~m})$

from a previous study [31] that, this phenomenon induced an increase heat transfer between the backfire and the fuel layer, and consequently promoted the relatively rapid propagation of the backfire. Because the in-draft flow has pushed fresh air towards the base of the backfire and induced an increase in the flame surface of the backfire, this increase of heat transfer can only be attributed to an increase of radiation between the flame and the unburned vegetation.

By comparing Figs. 6, 10 and 13, we can notice the significant impact of wind conditions upon the HRR, when the wind speed increased from $1 \mathrm{~m} / \mathrm{s}$ to $5 \mathrm{~m} / \mathrm{s}$, the maximum value of HRR (by summing the contributions due to the two fire fronts) increased from $280 \mathrm{MW}$ to $490 \mathrm{MW}$. Contrary to the situation observed for moderate wind conditions (see Fig. 7), the incoming wind flow has the possibility to cross the barrier formed by the fire front and to push the hot gases from the burning zone towards the unburned fuel located ahead of the fire front (see Fig. 14). In this way, the wind flow has contributed to enhance the heat transfer 


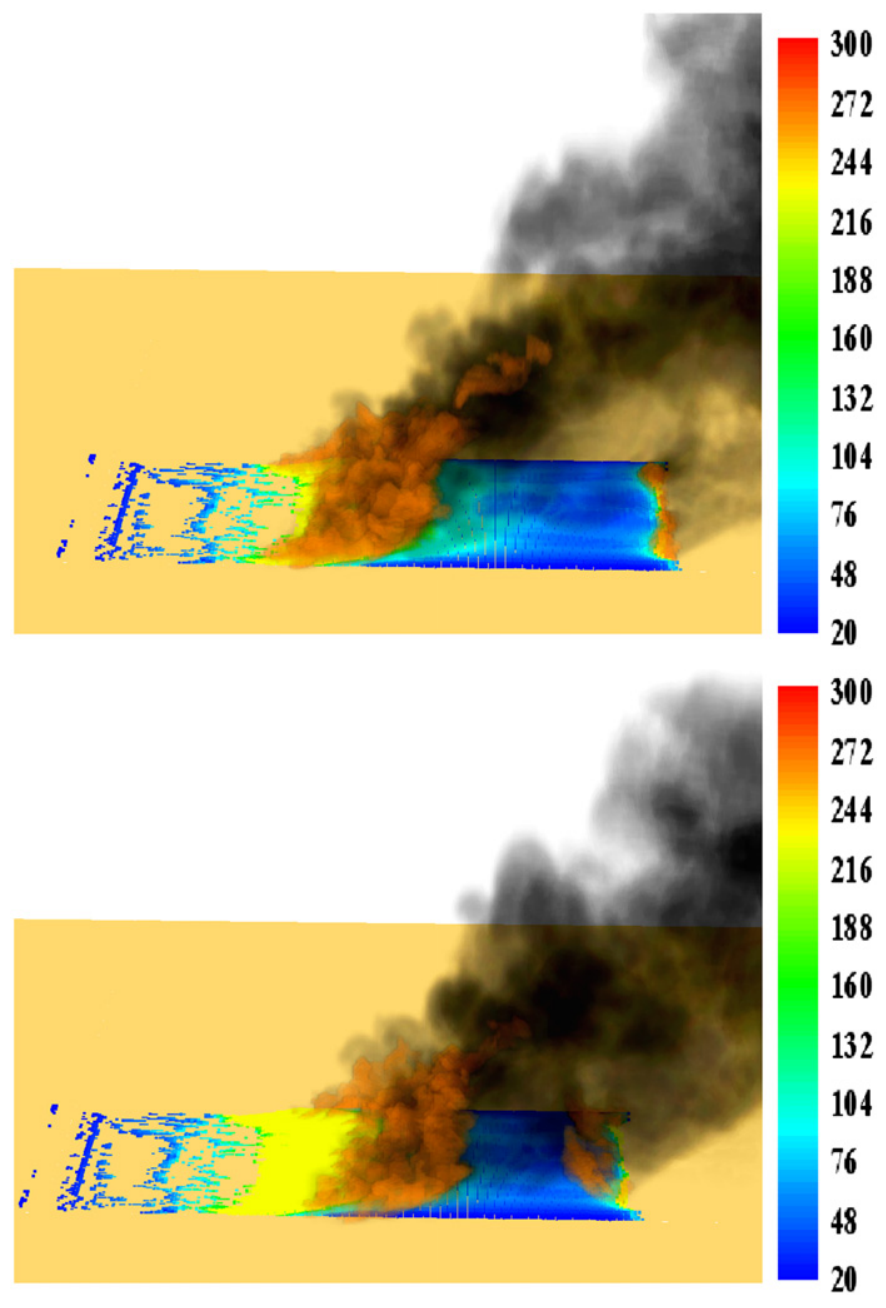

Fig. 12. Head fire and backfire propagating through grassland $\left(U_{10}=5 \mathrm{~m} / \mathrm{s}\right)$ at times $t=50 \mathrm{~s}$ (top) and $53 \mathrm{~s}$ (bottom). Heat release rate (in orange), smoke volume fraction (in black) and surface temperature $\left({ }^{\circ} \mathrm{C}\right.$ ) of solid fuel (in colour). (For interpretation of the references to colour in this figure legend, the reader is referred to the web version of this article.)

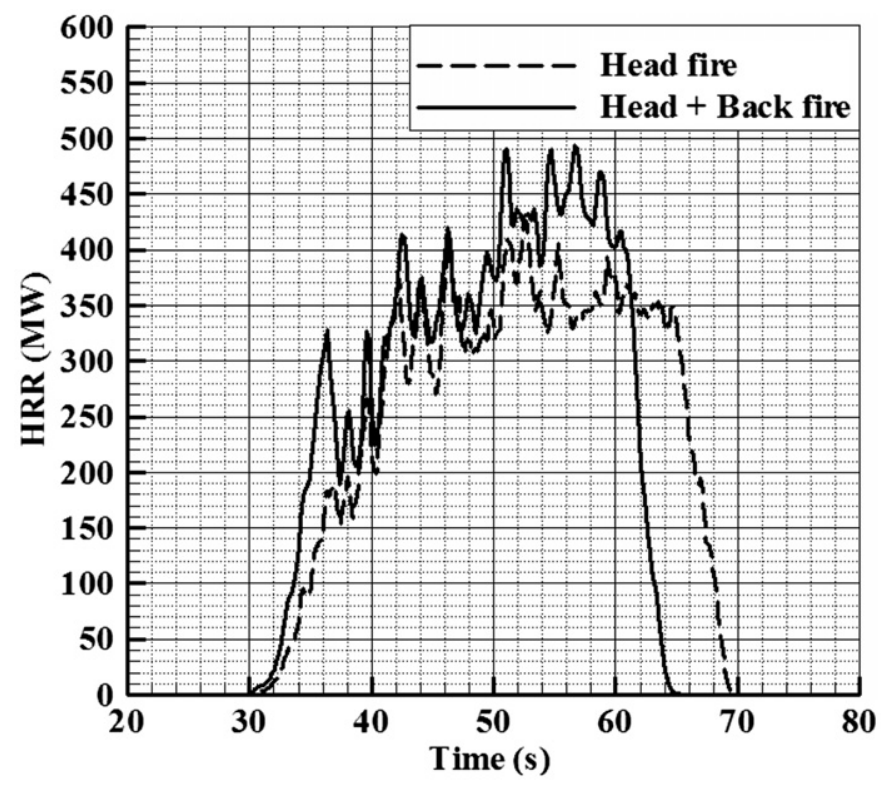

Fig. 13. Heat release rate (HRR) for a standalone head fire and for a head + backfire $\left(U_{10}=5 \mathrm{~m} / \mathrm{s}\right)$.
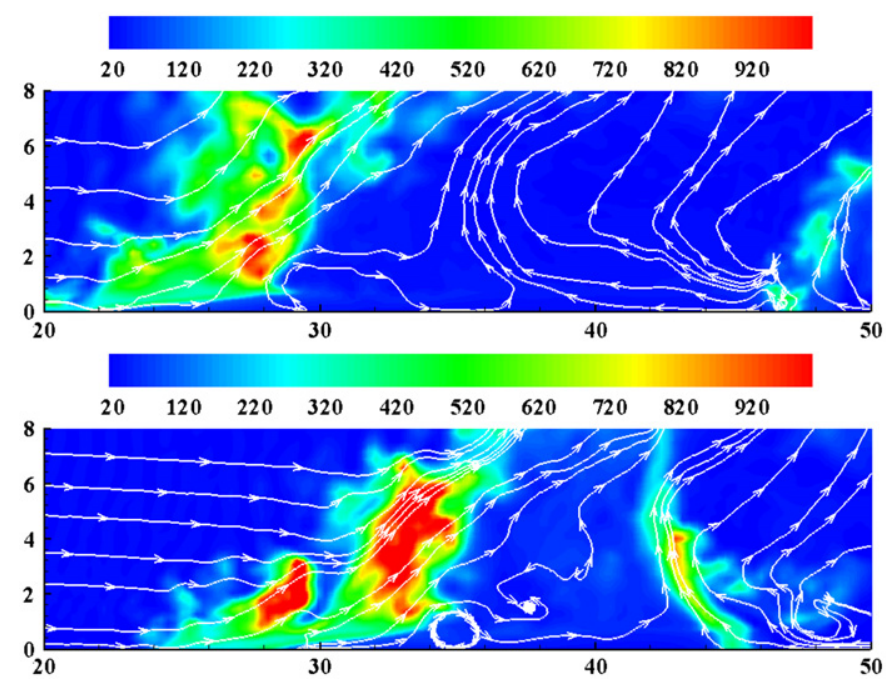

Fig. 14. Temperature field $\left({ }^{\circ} \mathrm{C}\right)$ and streamlines in a streamwise plane $\left(U_{10}=5 \mathrm{~m} /\right.$ s) at times $t=50 \mathrm{~s}$ and $53 \mathrm{~s}$ (plan $Y=-5 \mathrm{~m}$ ).



Fig. 15. Trajectories of the pyrolysis front (head fire and backfire) reconstituted from isotherm $T=500 \mathrm{~K}$ in the solid phase, for wind speeds $U_{10}=1,3,5$ and $8 \mathrm{~m} / \mathrm{s}$.

by convection and to extend the pyrolysis zone and the depth of the fire front (see Figs. 12 and 14) [31].

The time evolution of the position of the pyrolysis front (evaluated from the isothermal curve $T=500 \mathrm{~K}$ inside the solid phase) obtained for the four wind speed values, was reported in Fig. 15. The bottom part of the curve represents the pyrolysis front of head fires, and the top part is for backfires. The ROS of backfire and head fire were evaluated from the slope of the trajectories of pyrolysis fronts. The values were reported in Table 2. We can notice that backfires were not too much affected by the increase of wind velocity. This result confirms the idea that backfires were governed by radiation heat transfer and that because of the shelter effect played by head fires, the geometry of the flames (for backfire only) was not affected by the modifications of wind conditions. For head fires, until wind conditions can be considered as relatively moderate $\left(U_{10}=1\right.$ and $\left.3 \mathrm{~m} / \mathrm{s}\right)$, the ROS was not affected by the secondary ignition. For stronger wind conditions $\left(U_{10}=5 \mathrm{~m} / \mathrm{s}\right)$, the presence of backfire contributed to increase the ROS from $1.66 \mathrm{~m} / \mathrm{s}$ (standalone head fire case) to 
Table 2

Rate of spread (ROS) characterising the propagation of head fires (HF) and backfires (BF) for various wind speeds.

\begin{tabular}{lllll}
\hline$U_{10}(\mathrm{~m} / \mathrm{s})$ & 1 & 3 & 5 & 8 \\
$\operatorname{ROS}_{H F}(\mathrm{~m} / \mathrm{s})$ & 0.71 & 1.25 & 1.84 & 1.74 \\
$\operatorname{ROS}_{B F}(\mathrm{~m} / \mathrm{s})$ & 0.28 & 0.17 & 0.22 & 0.23 \\
\hline
\end{tabular}

$1.84 \mathrm{~m} / \mathrm{s}$ (head and back fires case), which is a $+10 \%$ increase. This result confirms that, before merging, the two fire fronts can mutually interact (two-way interaction).

\section{Conclusion}

A detailed physical wildfire model was used to simulate the interaction between a head fire and a backfire propagating through grassland. A preliminary study was carried out for a standalone fire and the results were compared with previous numerical results and experimental data from the literature. Then the configuration was extended to include a secondary line fire ignited at the downwind side of the plot. The numerical results highlighted that, in these conditions, the two fire fronts can interact at a relative shorter distance (ranging between 10 and $20 \mathrm{~m}$ ). The action of the head fire upon the backfire was not limited to the development of in-draft flow ahead of the main fire front, the presence of the thermal plume contributed also (shelter effect) to protect backfire from the direct impact of the wind flow. All these contributed in facilitating the propagation of the backfire. The interaction between the two fires can be qualified as having a significant two-way interaction. The influence of the backfire upon the head fire behaviour was also observed. All the present simulations were performed on a flat terrain, with a very dry vegetation $(\mathrm{FMC}=5 \%$ ). In these simulations, backfires did not propagate long enough to allow a sufficiently large distance between back fire ignition and the main fire front for safe operational use. The implication of this on guidance to field operations requires further validation of the WFDS model. The next step must be to study this problem in more operational and realistic conditions, for a slope terrain, with a less dry fuel, and for a heterogeneous fuel complex such as a shrubland vegetation layer.

\section{Acknowledgements}

This study was supported by the EU in the frame of the FIREPARADOX programme (FP6-018505).

\section{References}

[1] C. Chandler, Ph. Cheney, P. Thomas, L. Trabaud, Fire in Forestry, 1-2, John Wiley \& Sons, 1983

[2] J.G. Goldammer, C. De Ronde, Wildfire fire management handbook for subSahara Africa, Global Fire Monit. Cent. (GFMC) (2004) 432 pp.

[3] S.J. Pyne, P.L. Andrew, R.D. Laven, Introduction to Wildland Fire, 2nd Edition, John Wiley \& Sons, New York, 1996.

[4] E.S. Artsybashev, Forest Fires and Their Control, Russian Translation Series, A.A. Balkema, Rotterdam, 1985160 pp.

[5] W. Cui, Q. Qiao, Experimental studies of interactions between backfires and coming surface fires, For. Stud. China 4 (1) (2002) 25-28.

[6] J.A. Vega, E. Jiménez, J.R. Pérez, Effectiveness of Suppression Fires: Methods and First Results, Deliverable D2.3-2 of the Integrated Project FireParadox Project no. FP6-018505, European Commission, 2008, 27 pp.

[7] J.A. Vega, E. Jiménez, C. Fernandez, J.L. Dupuy, R.R. Linn, Effectiveness of Suppression Fires in Shrublands: Final Achievements, Deliverable D2.3-5 of the Integrated Project FireParadox, Project no. FP6-018505, European Commission, 2010, 24 pp.

[8] J.L. Dupuy, V. Konovalov, F. Pimont, J.A. Vega, E. Jiménez, R.R. Linn, Simulations of Interacting Fire Fronts. Deliverable D2.3-2 of the Integrated Project FireParadox, Project no. FP6-018505, European Commission, 2010, 25 pp.
[9] J.L. Dupuy, R.R. Linn, V. Konovalov, F. Pimont, J.A. Vega, E. Jiménez, Exploring three-dimensional coupled fire-atmosphere interactions downwind of winddriven surface fires and their influence on backfires using the HIGRADFIRETEC model, Int. J. Wildland Fire 20 (6) (2011) 734-750.

[10] R.R. Linn, J. Reisner, J.J. Colman, J. Winterkamp, Studying wildfire behaviour using FIRETEC, Int. J. Wildland Fire 11 (2002) 233-246.

[11] R. Roxburgh, G. Rein, Study of wildfire in-draft flows for counter fire operations, in: Proceedings of Forest Fire 2008, International Conference on Modelling, Monitoring and Management of Forest Fires, Toledo, Spain, 2008, 10 pp.

[12] D. Morvan, M. Larini, Modeling of one dimensional fire spread in pine needles with opposing air flow, Combust. Sci. Technol. 164 (2001) 37-64.

[13] D. Morvan, J.L. Dupuy, Modelling the propagation of a wildfire through a Mediterranean shrub using a multiphase formulation, Combust. Flame 138 (2004) 199-200.

[14] J.L. Coen Multiple fire interactions, in: Viegas, D.X. (Ed.), Proceedings of the Vth International Conference on Forest Fire Research, 2006.

[15] J.L. Coen, S. Mahalingam, J.W. Daily, Infrared imagery of crown-fire dynamics during FROSTFIRE, J. Appl. Meteorol. 43 (2004) 1241-1259.

[16] C.B. Clements, S. Zhong, S. Goodrick, J. Li, B.E. Potter, X. Bian, W.E. Heilman, J.J. Charney, R. Perna, M. Jang, D. Lee, M. Patel, S. Street, G. Aumann, Observing the dynamics of wildland grass fires: fireflux a field validation experiment, Bull. Am. Meteorol. Soc. 88 (9) (2007) 1369-1382.

[17] M. Fatehi, M. Kaviany, Adiabatic reverse combustion in a packed bed, Combust. Flame 99 (1994) 1-17.

[18] M. Larini, F. Giroud, B. Porterie, J.C. Loraud, A multiphase formulation for fire propagation in heterogeneous combustible media, Int. J. Heat Mass Transfer 41 (6-7) (1998) 881-897.

[19] D. Morvan, C. Hofman, F. Rego, W. Mell, Numerical simulation of the interaction between two fire fronts in the context of suppression fire operations, in: Proceedings of the 8th Symposium on Fire and Forest Meteorology, , Kalispell, MT-USA, 13-15 October (2009)

[20] D. Morvan, Physical phenomena and length scales governing the behaviour of wildfires: a case for physical modelling, Fire Technol. 47 (2011) 437-460.

[21] W.S.W. Trollope, L.A. Trollope, D.C. Hartnett, Fire behaviour a key factor in the fire ecology of African grasslands and Savannas, in: Viegas (Ed.), Forest Fire Research and Wildland Fire Safety, Millpress, Rotterdam, 2002.

[22] W.M. Pitts, Wind effects on fires, Prog. Energy Combust. Sci. 17 (1991) 83-134.

[24] D. Morvan, S. Méradji, W. Mell, 2011 Numerical study of the interaction between a head fire and a backfire propagating in grassland, in: Proceedings of the 10th International Symposium on Fire Safety Science, University of Maryland, USA, 19-24 June 2011, pp. 1415-1424.

[25] K.B. McGrattan, S. Hostikka, J. Floyd, H. Baum, R. Rehm, W. Mell, R. McDermott, Fire Dynamics Simulator Technical Reference Guide, Vol.1 Mathematical Model, NIST Special Publication 1018-5, National Institute of Standards and Technology, Gaithersburg, Maryland, September 2010. <http:// fire.nist.gov/fds/documentation.html $>$ (accessed 27.09.10).

[26] W. Mell, A. Maranghides, R. McDermott, S.L. Manzello, Numerical simulation and experiments of burning Douglas fir trees, Combust. Flame 156 (2009) 2023-2041.

[27] A.L. Sullivan, Wildland surface fire spread modelling, 1990-2007 I. Physical and quasi-physical models, Int. J. Wildland Fire 18 (4) (2009) 349-368.

[28] U. Hornung, Homogenisation and porous media, Interdisciplinary Applied Mathematics, Springer, 1996. 282 pp. (Chapter 6).

[29] W. Mell, M.A. Jenkins, J. Gould, Ph. Cheney, A physics-based approach to modelling grassland fires, Int. J. Wildland Fire 16 (1) (2007) 1-22.

[30] D. Morvan, S. Méradji, G. Accary, Wildfire behavior study in a Mediterranean pine stand using a physically based model, Combust. Sci. Technol. 180 (2008) 230-248.

[31] D. Morvan, S. Méradji, G. Accary, Physical modelling of fire spread in grasslands, Fire Saf. J. 44 (2009) 50-61.

[32] R.R. Linn, Ph. Cunningham, Numerical simulations of grass fires using a coupled atmosphere-fire model: basic fire behaviour and dependence on wind speed, J. Geophys. Res. 110 (2005) D13107, doi:10,1029.

[33] N.P. Cheney, J.S. Gould, W.R. Catchpole, The influence of fuel, weather and fire shape variables on fire spread in grasslands, Int. J. Wildland Fire 3 (1) (1993) 31-44.

[34] W. Mell, J.J. Charney, M.A. Jenkins, Ph. Cheney, J. Gould, Numerical simulations of grassland fire behaviour from the LANL-FIRETEC and NIST-WFDS models, in: EastFIRE Conference, George Mason University, Fairfax, VA, May 11-13 2005.

[35] P.J. Pagny, T.G. Peterson, Flame spread through porous fuel, Proc. Combus. Inst. 14 (1973) 1099-1107.

[36] R.W. Fox, A.T. McDonald, Ph.J. Pritchard, Introduction to Fluid Mechanics, 6th Edition, John Wiley \& Sons, New York, 2004

[37] R.C. Rothermel, Predicting behaviour and size of crown fires in the northern Rocky Mountain, USDA-RP-INT-438, 1991, $52 \mathrm{pp}$

[38] A.G. Mc Arthur, Grassland fire danger meter MkV, CSIRO Division of Forest Annual Report 1976-1977, 1977, 58 pp.

[39] P.L. Andrews, BehavePlus fire modelling system: past, present and future, in: Proceedings of the 7th Symposium on Fire and Forest Meteorological Society, Bar Harbor, Maine, 23-25 October 2007, 13 pp.

[40] M.F. Modest, Radiative Heat Transfer, 2nd Edition, Academic Press, New York, 2003.

[41] N.P. Cheney, J.S. Gould, Fire growth in grassland fuels, Int. J. Wildland Fire 5 (4) (1995) 237-247. 